\title{
Knowledge and attitude towards cervical cancer screening and associated factors among female Hawassa university college of medicine and health sciences students
}

\begin{abstract}
Background: Cancer of the cervix is the leading cause of cancer-related death next to breast cancer. Cervical cancer screening is a means for early detection and treatment of the problem before it advances to a later stage. However, cervical cancer screening rate is not satisfactory in many countries including Ethiopia. Therefore, this study aimed to assess the knowledge and attitude towards cervical cancer screening and associated factors among female Hawassa University College of Medicine and health sciences students.
\end{abstract}

Methods: An institution based cross-sectional study conducted using simple random sampling technique from Aprill ${ }^{\text {st }}$ to $30^{\text {th }}$ 2016. Three hundred eighty female students participated in the study. Descriptive statistics and binary logistic regression used to describe each variable and to identify the presence of an association between independent variables with outcome variable respectively. Adjusted odds ratio with $95 \%$ confidence interval and $p$-value $<0.05$ used to determine the association.

Result: A total of 380 participate in the study with the response rate of $90 \%$. The majority, 202(53.2), of the respondents, belongs to the age group21-23 years old. Two hundred sixteen $(56.8 \%)$ Knowledgeable and $210(55.3 \%)$ had a positive attitude toward cervical cancer screening. Age, year of study, school category, and income significantly associated with knowledge of cervical cancer screening. Age, year of study, religion, knowing Human papillomavirus as a cause for cervical cancer significantly associated with the attitude towards cervical cancer screening.

Conclusion: Half of the respondents were Knowledgeable and had a positive attitude towards cervical cancer screening. Age, year of study, school category, and income identified as significantly associated factors for knowledge of cervical cancer screening. Age, year of study, religion, knowledge about Human papillomavirus are associated considerably with the attitude towards cervical cancer screening.

Keywords: knowledge, attitude, cervical cancer, associated factors, Hawassa university
Volume 7 Issue 3 - 2018

\author{
Shimeles Tsegaye,' Daniel Mengistu, ${ }^{2}$ \\ Teklemariam Gultie ${ }^{3}$ \\ 'Department of Midwifery, Dilla University, Ethiopia \\ ${ }^{2}$ School of Nursing and Midwifery, Addis Ababa University, \\ Ethiopia \\ ${ }^{3}$ Department of Midwifery,Arba Minch University, Ethiopia
}

Correspondence: Teklemariam Gultie, Department of Midwifery, Arba Minch university, Arba Minch, Ethiopia, Tel +251912786647, Email tekledb2002@gmail.com

Received: May 12, 2018 | Published: June 26, 2018
Abbreviations: WHO, world health organization; HPV, human papillomavirus; STD, sexually transmitted diseases; HIV, human immune virus; AIDS, Acquired immune disease syndrome; OR, odds ratio; VIA, visual inspection with acetic acid; $\mathrm{CI}$, confidence interval

\section{Background}

Worldwide, cancer of the cervix is the major leading cause of cancer death in women after breast cancer. Each year, half-million new cases are diagnosed and approximately 274,000 deaths due to cervical cancer in 2008. It is the most common malignancy among females in developing countries. Cancer of the cervix is the most common female cancer, and approximately half a million women develop cervical cancer each year, with an estimated $80 \%$ or more occurring in developing countries. ${ }^{1,2}$ Cervical cancer is the most common and lethal among women in Sub-Saharan Africa, second only to breast cancer in northern Africa. ${ }^{3}$ In South Africa, cervical cancer is the most common cancer in black women and fourth among white women. Although cervical cancer remains a significant cause of morbidity and mortality among women in developing countries, the patients were present with advanced disease. ${ }^{4}$
The epidemiologic risk factors for cervical cancer are: having multiple sexual partners, early onset of sexual activity, Human papillomavirus (HPV) infection, lower genital tract neoplasia, or prior sexual exposure to someone with cervical neoplasia, a history of Sexually Transmitted Diseases (STDs),cigarette smoking, human immunodeficiency virus (HIV) infection, other forms of immunosuppression and long-term oral contraceptive pill use. ${ }^{5}$ A considerable reduction in cervical cancer incidence and deaths achieved in developed countries with systematic cytological screening programs. Thus, it is largely preventable by effective screening programs. However, this has not been possible in most limited resource countries, mainly because systematic screening is rarely performed. ${ }^{6,7}$ In Ethiopia, Cervical Cancer ranks as the second most frequent cancer among women between 15 and 44years of age. Every year 4648 women are diagnosed with cervical cancer, and 3,235 dies from the disease. ${ }^{8}$

In Ethiopia among the general population, about $33.6 \%$ of women estimated to harbor cervical HPV infection at a given time. From those, 7,095 new cervical cancer cases diagnosed annually. However, data is not yet available on the HPV burden in the general population of Ethiopia; current estimate indicates that every year 
4,648 woman diagnosed with cervical cancer and 3,235 die from the disease. Cervical cancer ranks as the 2 nd most frequent cancer among women between 15 and 44years of age. ${ }^{8}$ According to the 2009 world health organization (WHO) report, the age-adjusted incidence rate of cervical cancer in Ethiopia is 35.9 per 100,000 patients with 7,619 annual number of new cases and 6,081 deaths every year. Despite this fact, very few women receive cervical cancer screening services in Ethiopia. ${ }^{9,10}$ Much of the recent research identify low levels of knowledge, is believed, to contribute low rates of screening uptake in the populations. To date, however, little attention has been directed toward assessing women's knowledge in countries where mass screening has long been implemented as a matter of public policy and where general uptake rates are consistently high. ${ }^{11}$

Cervical cancer screening has consistently shown to be effective in reducing the incidence rate or the occurrence of new cervical cancer cases and mortality from the disease. However, cervical cancer screening attendance rate is still far from satisfactory in many countries. Perhaps, challenges of cervical cancer screening in developing countries include limited access to health services and labs, no screening programs, limited or non-existent awareness among populations and health workers, limited or no access to diagnostics and laboratories, poor referral and follow up etc. Analysis of population-based surveys indicates that coverage of cervical cancer screening in developing countries is $19 \%$ compared to $63 \%$ in developed countries. ${ }^{12,13}$ Most women present with advanced stages of cervical cancer with poor prognosis. Thus, in Ethiopia, only $0.6 \%$ of all women, $1.6 \%$ of urban and $0.4 \%$ of rural women aged $18-69$ years screened every three years. The major factors are; inadequate knowledge about the disease process, and Pap smear testing and clients' negative attitude towards the procedure. Besides, Poor knowledge about cervical cancer and lack of awareness of available screening methods have been identified as the most important factors hindering the use of available cervical cancer screening services. ${ }^{13-15}$

\section{Methodology}

\section{Study setting and period}

The study conducted in Hawassa University College of Medicine and Health Sciences, which is in Hawassa the capital city of southern nation, nationalities and people's regional state. This College was one of the six campuses of the Hawassa University, established in 1996 at the former Dilla College of Teacher Education and Health Sciences in Dilla then move to Hawassa city in 2003. It is located at the south end of the town. The college has been involved both in academic and community services through its referral hospital and different academic schools and departments. Currently, the College has three schools, i.e. school of nursing and midwifery, school of medicine, and school of public and environmental health and one department (department of medical laboratory) with a total of 2,617students (1,884 male \& 733 female). The college has run both undergraduate and graduate programs. The study conducted from April 1 to 302016.

\section{Study design}

Institutional based cross-sectional study conducted.

\section{Source and study population}

The source population was all undergraduate female students who enrolled in Hawassa University College of Medicine and Health. The study population comprised of undergraduate female students randomly selected from different departments in Hawassa University College of Medicine and Health Sciences. Those students who were sick during the time of data collection excluded from the study.

\section{Sample size determination}

The single population proportion formula used to calculate the sample size for knowledge and attitude towards cervical cancer screening. Considering the proportion of female who are knowledgeable and having a positive attitude towards cervical cancer screening is $50 \%$ and adding $10 \%$ of non-response rate. Considering the assumption of a $95 \%$ confidence level and a $5 \%$ margin of error the final sample size was 422 .

\section{Sampling method}

To obtain a representative sample, simple random sampling applied to select study participants from the source population. All schools and departments in the college identified. The calculated sample size was distributed to each School and Department in the College using probability proportional to size (PPS). Also, the numbers of female students required for the study in each School and Department were determined. The sample size for each School and Department computed.

\section{Data collection methods}

The data collection instrument was pre-tested and anonymous self-administered structured questionnaire, which was adopted and modified after reviewing different kinds of literature. The questioner was prepared in English. The questionnaire contains of three sections. The first section contained information on the socio- demographic characteristics of the study participants. The second section used to assess knowledge of study participants about cervical cancer screening; the third section was also evaluating their attitude towards cervical cancer screening.

The data collection facilitated by six female data collectors who have diploma midwives and three supervisors with first degree in Midwives with possible experience in data collection in previous similar studies. Training is given for data collectors and supervisor before the pretest on the objective of the study, the contents of the questionnaire, issue related to the confidentiality of the response and the right of the respondents.

The pretest of the instrument was carried out on 40 Students in Dilla University College of Health Sciences, and after pre-test, discussions were carried and based on the experience gained through the pre-test amendment to the questionnaire was made. The principal investigator, the department heads, and School Deans were arranging data collection days before to the data collection and gather the selected students to free rooms on the day of collection. The data collected after informed consent obtained from respondents. Moreover, teachers and college authorities were not involved in administering the questionnaire and not allowed to enter into data collection room during data collection to assure the privacy of participants. Additionally, to overcome information contamination data collected from all students from selected school simultaneously. Finally, data reviewed and checked for completeness and consistency by the supervisors and principal investigator after.

\section{Data analysis procedure}

For data processing and analysis SPSS version 20 was used. Data 
checked for completeness and consistency. Coded data entered into the computer programs after the required cleaning done. Frequency distribution tables used to describe most of the findings and graphs plotted for some accordingly, and other descriptive summaries were calculated. Univariate and then multivariate analysis carried out. Odds ratio (OR) with confidence intervals and p-values was calculated. A multivariable analysis performed to control confounding variables and identify major factors determining knowledge, attitude, and utilization of cervical cancer screening services. The output of the analysis was given and odds ratio with their respective confidence intervals. AP value of less than 0.05 was taken as the level of significance.

\section{Results}

\section{Socio-demographic characteristics of the study} population

Out of the total of 422 study participants, 42 returned the questionnaires incomplete and with an inconsistent response. After excluding incomplete and inconsistent questionnaires, the analysis was done on the remaining questionnaires making the overall response rate of $90 \%$. The age of the participants were 18 to 26years with mean age of 21.5. Majorities, 202(53.2\%), of the respondents, were in the age group between 21-23years. Regarding school of enrolment, $222(58.4 \%), 95(25 \%)$ and $63(16.6 \%)$ were from the school of Medicine, School of Nursing and Midwifery and school of public health respectively. The year of study distribution of students were $145(38.2 \%)$ first and second $120(31.6 \%)$ third year and the remaining $115(30.3 \%)$ were $4^{\text {th }}$ year and above. Two hundred and sixty-six $(70 \%)$ of the study participants were Orthodox Christian followed by Protestants and Muslim religion followers 58(15.3\%) and 39(10.3\%) respectively. Regarding ethnic group distribution, 110(28.9\%) were Amhara, 91(23.9\%) were Gurage and 82(21.6\%) were Oromo. Half of the study participants had at 450 Ethiopian birrs monthly income (Table 1).

Table I Sociodemographic characteristics of female students in Hawassa University College of Medicine and Health Sciences, Hawassa, Ethiopia, 2015 $(n=380)$

\begin{tabular}{llll}
\hline Variables & $\begin{array}{l}\text { Response } \\
\text { category }\end{array}$ & Frequency & Percentage (\%) \\
\hline \multirow{4}{*}{ Age group } & $17-20$ & 127 & 33.4 \\
& $21-23$ & 202 & 53.2 \\
& $24-26$ & 51 & 13.4 \\
& Orthodox & 266 & 70 \\
& Protestant & 58 & 15.3 \\
& Catholic & 13 & 3.4 \\
& Muslim & 39 & 10.3 \\
& Other** & 4 & 1.1 \\
& Amhara & 110 & 28.9 \\
& Gurage & 91 & 23.9 \\
& Oromo & 82 & 21.6 \\
& Tigray & 35 & 9.2 \\
& Sidama & 26 & 6.8 \\
& Wolayita & 23 & 6.1 \\
& Other* & 13 & 3.5
\end{tabular}

\begin{tabular}{llll} 
& $\begin{array}{l}<450 \text { Ethiopian } \\
\text { birr*** }\end{array}$ & 194 & 51.1 \\
$\begin{array}{l}\text { Income } \\
\text { category }\end{array}$ & $\begin{array}{l}\text { Ethiopian Birr } \\
>901 \text { Ethiopian }\end{array}$ & 122 & 32.1 \\
& Birr & 64 & 16.8 \\
Are you & Yes & 12 & 3.2 \\
married? & No & 368 & 96.8 \\
\hline
\end{tabular}

Note* Hadiya $(n=10)$ and Gamo $(n=3) * *$ Adventist $(n=4) * * * 22$ Ethiopian birr= I USD

\section{Sexual and reproductive characteristics}

Ninety-four (24.7\%) respondents had asexual partner and 79(20.8 $\%$ ) of them had had sexual intercourse with the median age of first sexual intercourse 19years old. Among those ever-had sexual intercourse, 34(43\%) were started their first sexual intercourse at the age of less than 19years. Sixty-eight of them ever had sex with one partner (Table 2).

Table 2 Sexual and reproductive history of female students in Hawassa University College of Medicine and Health Sciences, Hawassa, Ethiopia, 2015 $(n=380)$

\begin{tabular}{llll}
\hline Variables & $\begin{array}{l}\text { Response } \\
\text { category }\end{array}$ & Frequency & $\begin{array}{l}\text { Percentage } \\
\text { (\%) }\end{array}$ \\
\hline Had sexual partner & Yes & 94 & 24.7 \\
& No & 286 & 75.3 \\
Had sexual & Yes & 79 & 20.8 \\
intercourse & No & 301 & 79.2 \\
& $17-18$ & 34 & 43 \\
Age of Ist & 19 & 24 & 30.4 \\
intercourse ( $=79$ & $>=20$ & 21 & 26.6 \\
Number of sexual & One & 68 & 86.1 \\
partners you & Two & 5 & 6.3 \\
had intercourse & Three & 3 & 3.8 \\
before(n=79) & More than three & 3 & 3.8 \\
Have you been & Yes & 8 & 2.1 \\
pregnant before & No & 372 & 97.9 \\
\hline
\end{tabular}

\section{Knowledge about cervical cancer screening}

Two hundred ninety-two $(76.8 \%)$ heard about cervical cancer. Of those who had heard about cervical cancer, a higher proportion of students knew about causes, symptoms and its prevention. Among those who had heard about cervical cancer majority of the respondents were in the age range of 21-23years. The most widely and consistently responded screening method was Pap smear. Two hundred two $(53.2 \%)$ of the study participants knew Pap smear, and only $178(21.6 \%)$ knew about VIA and responded as the screening method for cervical cancer. More than half of the respondents knew about risk factors, symptoms, prevention and treatment of methods for cervical cancer. The overall respondent's knowledge towards cervical cancer categorized as Knowledgeable and not Knowledgeable using the mean score of the respondents on the knowledge part questions. Two hundred sixteen (56.8\%) of the respondents were Knowledgeable. Regarding their source of information about cervical cancer teachers, media like Television, radio, books and health worker were the major source of information. The least indicated source was family members (Table 3). 
Table 3 Knowledge about cervical cancer among female students in Hawassa University College of Medicine and Health Sciences, Ethiopia, 20I5 ( $n=380$ )

\begin{tabular}{|c|c|c|c|}
\hline Variables & Response category & Number & Percentage (\%) \\
\hline \multirow{2}{*}{$\begin{array}{l}\text { Have you ever heard about cervical } \\
\text { cancer? }\end{array}$} & Yes & 292 & 76.8 \\
\hline & No & 88 & 23.2 \\
\hline \multirow{4}{*}{$\begin{array}{l}\text { Do you know any causes of } \\
\text { Cervical Cancer? }\end{array}$} & Yes & 258 & 67.9 \\
\hline & No & 122 & 32.1 \\
\hline & Initiation of intercourse at Early age & 180 & 47.4 \\
\hline & Having Multiple sexual partners & 189 & 49.7 \\
\hline \multirow{5}{*}{$\begin{array}{l}\text { What are the causes of cervical } \\
\text { cancer? }\end{array}$} & $\begin{array}{l}\text { Having intercourse with person who has } \\
\text { cervical } \mathrm{Ca}\end{array}$ & 124 & 32.6 \\
\hline & Sexual transmitted infection(STI) & 150 & 39.5 \\
\hline & HIV infection & 149 & 39.2 \\
\hline & Human papilloma virus(HPV) & 189 & 49.7 \\
\hline & Old age & 51 & 13.4 \\
\hline \multirow{2}{*}{$\begin{array}{l}\text { Have ever heard about cervical } \\
\text { smear? }\end{array}$} & Yes & 202 & 53.2 \\
\hline & No & 178 & 46.8 \\
\hline \multirow{2}{*}{$\begin{array}{l}\text { Do you know how to prevent } \\
\text { cervical cancer? }\end{array}$} & Yes & 265 & 69.7 \\
\hline & No & 115 & 30.3 \\
\hline \multirow{3}{*}{$\begin{array}{l}\text { What are the preventive } \\
\text { mechanisms of cervical cancer? }\end{array}$} & Avoiding multiple sexual partners & 211 & 55.5 \\
\hline & Avoiding HPV infection & 214 & 56.3 \\
\hline & Vaccination against HPV & 195 & 51.3 \\
\hline \multirow{2}{*}{$\begin{array}{l}\text { Do you know how to treat } \\
\text { Cervical Cancer? }\end{array}$} & Yes & 260 & 68.4 \\
\hline & No & 120 & 31.6 \\
\hline \multirow{3}{*}{$\begin{array}{l}\text { What is the treatment option for } \\
\text { cervical ca? }\end{array}$} & Surgery & 184 & 48.4 \\
\hline & Chemotherapy & 170 & 44.7 \\
\hline & Radiotherapy & 117 & 30.8 \\
\hline
\end{tabular}

\section{Factors associated with knowledge about cervical cancer screening}

Socio-demographic characteristics of respondents about knowledge towards cervical cancer screening were analyzed using bivariate logistic regression. A significant difference in the knowledge of respondents among a different group of age, year of study/ educational level, school and income of the respondents entered into the model. A group of respondents with age group 21-23years 11 times $(\mathrm{COR}=11.47$; 95\%CI $6.69-19.64)$ more likely to be knowledgeable than students with age group 17-20years. Also, 24 and above years 19 times $(\mathrm{COR}=19 ; 95 \% \mathrm{CI} 8.20-44.20)$ more likely to be knowledgeable as compared to students with age group 17-20 years old. Also, year three students 47 times $(\mathrm{COR}=47.86$; 95\% CI 22.85-100.24) more likely to be knowledgeable than $1^{\text {st }}$ and $2^{\text {nd }}$-year students. Moreover school of Nursing and Midwifery $(\mathrm{COR}=2 ; 95 \% \mathrm{CI} 0.63-6.35)$, School of Medicine (COR=1.20; 95\% CI 0.31- 4.60). Moreover, the income of the respondents identified as having significant association with knowledge of respondents towards cervical cancer screening.

Multivariable Logistic regression analysis performed to examine the association between Socio-demographic, characteristics of participants and certain variables about knowledge towards cervical cancer screening. Year of study and schools were significantly associated with the respondent's knowledge towards cervical cancer screening. Year three students ( $\mathrm{AOR}=48.83 ; 95 \% \mathrm{CI} 19.13-124.63$ ) and $\geq$ year four students $(\mathrm{AOR}=98.29 ; 95 \% \mathrm{CI} 31.67-305.03)$ more likely to be knowledgeable as compared to first and second-year students. Participant from the school of medicine (AOR $=3.56$; $95 \%$ CI [1.56-8.10] were more likely to be knowledgeable than participants form school of public health (Table 4). 
Table 4 Determinant factors for knowledge about cervical cancer screening among female students in Hawassa University College of Medicine and Health Sciences, Hawassa Ethiopia, 2015

\begin{tabular}{|c|c|c|c|c|c|}
\hline \multirow{2}{*}{ Variables } & & \multicolumn{2}{|c|}{ Knowledge } & \multirow{2}{*}{$\begin{array}{l}\text { Crude OR } \\
(95 \% \mathrm{CI})\end{array}$} & \multirow{2}{*}{$\begin{array}{l}\text { Adjusted OR } \\
(95 \% \mathrm{CI})\end{array}$} \\
\hline & & Knowledgeable & Not-knowledgeable & & \\
\hline \multirow{3}{*}{ Age } & $21-23$ & 149 & 53 & II.47(6.69-19.64)* & I.07 (0.4I-2.75) \\
\hline & $24-26$ & 42 & 9 & $19(8.20-44.2)$ & $1.20(0.28-5.05)$ \\
\hline & $17-20$ & 25 & 102 & I & I \\
\hline \multirow{3}{*}{ Income } & $<450$ & 102 & 92 & $0.46(0.25-0.85)$ & $\mathrm{I} .00(0.35-2.8 \mathrm{I})$ \\
\hline & $45 I-900$ & 69 & 53 & $0.55(0.28-1.04)^{*}$ & $0.90(0.3 \mid-2.59)$ \\
\hline & $>901$ & 45 & 19 & I & I \\
\hline \multirow{3}{*}{$\begin{array}{l}\text { Year of } \\
\text { study }\end{array}$} & $3 r d$ year & 99 & 21 & $47.86(22.85-100.24)^{*}$ & $48.83(19.13-124.63)^{* *}$ \\
\hline & $>=4$ year & 104 & II & $96.00(41.31-223.05)^{*}$ & $98.29(31.67-305.03)^{* *}$ \\
\hline & $<=2$ nd year & 13 & 132 & I & I \\
\hline \multirow{3}{*}{ School } & $\begin{array}{l}\text { Nursing \& } \\
\text { midwifery }\end{array}$ & 32 & 63 & $2(0.63-6.35)$ & $2.26(0.82-6.20)$ \\
\hline & Medicine & 152 & 70 & $1.2(0.3 \mid-4.6)$ & $3.56(1.56-8.10)^{* *}$ \\
\hline & Public health & 32 & 31 & I & I \\
\hline
\end{tabular}

** Significant at $\mathrm{p}$-value $<0.05$, HPV, human papilloma virus; OR, odds ratio.

\section{Attitudes of respondents towards cervical cancer screening}

Six questions put on Likert's scale to assess the attitude of participants towards cervical cancer screening. Two hundred ten $(55.3 \%)$ of the respondents had positive attitude towards cervical cancer screening. Of those who had a positive attitude, 124(59\%) students were from the school of medicine, 51(24.2\%) from school of nursing and midwifery and $16.8 \%$ from the school of public health. Based on the respondent's score on the attitude question, the minimum and maximum score on the attitude questions by the respondents were seven and 30 respectively (Table 5).

Table 5 Female student`s Attitude towards cervical cancer screening in Hawassa University College of Medicine and Health Sciences, Hawassa Ethiopia, 20 I5

\begin{tabular}{|c|c|c|c|}
\hline \multirow{2}{*}{ Variables } & \multirow{2}{*}{ Response category } & \multicolumn{2}{|c|}{ Attitude } \\
\hline & & Positive $(n=210)$ & Negative $(n=\mid 70)$ \\
\hline \multirow{3}{*}{ Schools } & school of Nursing and Midwifery & $5 \mathrm{I}(24.3)$ & $44(25.9)$ \\
\hline & School of Medicine & $124(59)$ & $98(57.6)$ \\
\hline & School of Public health & $35(16.7)$ & $28(16.5)$ \\
\hline \multirow[t]{3}{*}{ Respondents Age group } & $17-20$ & $93(44.3)$ & $34(20)$ \\
\hline & $21-23$ & $95(45.2)$ & $107(62.9)$ \\
\hline & $24-26$ & $22(10.5)$ & $29(17.1)$ \\
\hline \multirow[t]{3}{*}{ Year of study } & $<=2$ nd year & $112(53.3)$ & $33(19.4)$ \\
\hline & $3 r d$ year & 67(31.9) & $53(3 \mid .2)$ \\
\hline & $>=4$ th year & $3 I(14.8)$ & $84(49.4)$ \\
\hline
\end{tabular}

Factors associated with the attitude towards cervical cancer screening

The bivariate logistic regression analysis showed that there was a significant association between age, year of study, religion, knowledge on importance/benefits of cervical cancer screening, knowledge about cervical cancer and knowledge about HPV of respondents with the attitude towards cervical cancer screening. This analysis showed age $17-20$ years $(\mathrm{COR}=3.60 ; 95 \%$ CI $1.82-7.11)$ were more likely to have positive attitude. In addition, year three students $67 \%$ ( $\mathrm{COR}=0.37 ; 95 \% \mathrm{CI} 0.21-0.63$ ), more likely to have positive attitude. Participants who were Knowledgeable on benefits of cervical cancer screening $82 \%$ (COR $=0.18$; 95\% CI $0.11-0.29)$, knowledge about cervical cancer $66 \%(\mathrm{COR}=0.34 ; 95 \%$ CI $0.20-0.59)$ and knowledge on HPV69\% (COR $=0.31 ; 95 \%$ CI $0.20-0.47)$ more likely to have positive attitude (Table 6). Multivariable Logistic regression analysis 
performed to examine the association between Socio-demographic, characteristics of participants and their attitude towards cervical cancer screening. The analysis showed that year of study i.e. thirdyear student was $70 \%(\mathrm{AOR}=0.31 ; 95 \%$ CI $0.13-0.75)$ more likely to have positive attitude towards cervical cancer screening than second and first-year students. Protestant religion followers 2.78 times (AOR
$=2.78 ; 95 \%$ CI $1.37-5.64)$ more likely to have positive attitude than orthodox followers. A participant who knew the benefits of cervical cancer screening $80 \%$ ( $\mathrm{AOR}=0.37 ; 95 \%$ CI $0.21-0.66$ ) more likely to have positive attitude towards cervical cancer screening than their counter parts (Table 6).

Table 6 Attitude towards cervical cancer screening and its associated factors among female students in Hawassa University College of Medicine and Health Sciences, Hawassa Ethiopia, 2015

\begin{tabular}{|c|c|c|c|c|c|}
\hline \multirow[b]{2}{*}{ Variables } & & \multicolumn{2}{|c|}{ Attitude } & \multirow{2}{*}{$\begin{array}{l}\text { Crude OR } \\
(95 \% \mathrm{Cl})\end{array}$} & \multirow{2}{*}{$\begin{array}{l}\text { Adjusted OR } \\
(95 \% \mathrm{Cl})\end{array}$} \\
\hline & & $\begin{array}{l}\text { Positive } \\
\text { attitude }\end{array}$ & $\begin{array}{l}\text { Negative } \\
\text { attitude }\end{array}$ & & \\
\hline \multirow{3}{*}{ Age } & $17-20$ & 93 & 34 & $3.60(I .82-7.1 \mathrm{I}) *$ & $0.38(0.14-1.05)$ \\
\hline & $21-23$ & 95 & 107 & $1.17(0.63-2.17)$ & $0.48(0.22-1.040$ \\
\hline & $24-26$ & 22 & 29 & I & 1 \\
\hline \multirow{3}{*}{ Year of study } & 3rdyear & 67 & 53 & $0.3790 .21-0.63)^{*}$ & $0.31(0.13-0.75)^{* *}$ \\
\hline & $>=4$ year & 31 & 84 & $0.10(0.06-0.19)^{*}$ & $0.06(0.02-0.17)^{* *}$ \\
\hline & $<=2$ ndyear & 112 & 33 & I & 1 \\
\hline \multirow{4}{*}{ Religion } & Protestant & 41 & 17 & $2.52(1.36-4.66)^{*}$ & $2.78(1.37-5.64)^{* *}$ \\
\hline & Muslim & 27 & 12 & $2.35(1.14-4.84)^{*}$ & $3.29(1.44-7.54)^{* *}$ \\
\hline & catholic & 10 & 3 & I.04(0.14-7.53) & $10.97(2.50-48.19)^{* *}$ \\
\hline & orthodox & 130 & 136 & I & I \\
\hline \multirow{2}{*}{ Know benefits of screening } & Yes & 83 & 132 & $0.18(0.11-0.29)^{*}$ & $0.37(0.21-0.66)^{* *}$ \\
\hline & No & 127 & 38 & I & I \\
\hline \multirow{2}{*}{ Heard about Cervical cancer } & Yes & 145 & 147 & $0.34(0.20-0.59)$ & $0.70(0.34-I .42)$ \\
\hline & No & 65 & 23 & I & I \\
\hline \multirow{2}{*}{$\begin{array}{l}\mathrm{HPV} \text { is a Cause for cervical } \\
\text { cancer }\end{array}$} & Yes & 78 & 111 & $0.3 I(0.20-0.47)$ & $1.13(0.57-2.23)$ \\
\hline & No & 132 & 59 & I & 1 \\
\hline
\end{tabular}

** Significant at $\mathrm{p}$-value $<0.05$, HPV, Human papilloma virus; OR, odds ratio

\section{Discussion}

This study conducted to assess the knowledge and attitude towards cervical cancer screening and its associated factors among female students in Hawassa University College of Medicine and Health Sciences. The findings of this study showed that majority, 292(76.8\%), of the study participants had heard about cervical cancer. Which is somehow lower when compared with other similar study done in Ukraine among female medical students of Crimea State Medical University where $80 \%$ of the respondents had heard about cervical cancer. ${ }^{16}$ This gap might be due to the availability of the cervical cancer screening service and the information dissemination through different mass media is better in Ukraine than the present study setting. The knowledge of participants on cervical cancer indicated that $67.9 \%$ of respondents know risk factors for cervical cancer Among these risk factors having multiple sexual partners, initiation of sexual intercourse at early age and Human papilloma virus were mainly reported risk factors for cervical cancer. This result is lower than the previous study done in Ukraine, Malaysia, Bhutan and South Africa. ${ }^{16-18}$ The difference could be due to the inaccessibility of cervical cancer screening service as well as low attention was given in the present study setting compared to the others study.
Regarding Knowledge of symptoms of cervical cancer, 258(67.9\%) of the participants knew the symptoms such as vaginal bleeding between periods, painful coitus and bleeding after intercourse reported by $52.6 \%, 46.3 \%$ and $44.7 \%$ of respondents respectively. This finding is similar to other studies done in Malaysia. ${ }^{17}$ Regarding the sexual activity, 79(20\%) respondents were having sexual intercourse, and among those ever-had intercourse, 68(86.1\%) had intercourse with only one partner. These figures are less than other similar study done in other African and sub-Saharan African female students. A study done in South Africa among female university students indicated that $28 \%$ of the respondents had multiple sexual partners. On the other study done among undergraduate students in Nigeria found that $54 \%$ were sexually active and $43 \%$ had multiple sexual partners. ${ }^{19}$ This variation could be due to differences in the population's exposure to technology, culture, and the participant's residence area. Regarding the source of information about cervical cancer for the student's, majority of the students indicated (55.5\%) mentioned teachers, $(30.5 \%)$ mass media and $22.9 \%$ of participants' health worker as their source of information for cervical cancer and its screening. Which is comparable with the study findings in Addis Ababa among women who visited selected hospitals. ${ }^{2}$ This figure may also have indicated that health workers and media were not doing as expected and had to 
contribute more to the education and information on cervical cancer screening.

According to this study, there is a significant association between year of study and knowledge of the respondents towards cervical cancer screening. Year three students in the university were fortyeight times more likely to be knowledgeable about cervical cancer as compared to first and second-year students. Those students in $4^{\text {th }}, 5^{\text {th }}$ and $6^{\text {th }}$ years of study were ninety-eight times knew more about cervical cancer screening than first and second-year students. Also, students from school of medicine were more likely to be knowledgeable about cervical cancer than those from school of public health. This may indicate the student's level of exposure to different medical courses that may influence their knowledge level towards cervical cancer screening. The attitude of the study participants indicated that $210(55.3 \%)$ of them had a positive attitude. Which is lower than a similar study done among reproductive health clients in Addis Ababa selected hospitals. ${ }^{2}$ Also, the remaining 170(44.7\%) of the female students had a negative attitude towards prevention and screening of cervical cancer. This could be due to the reason that at the time of the previous studies was conducted the concern of the community and the government towards cervical cancer was not that much as compared with the present situation. Recently the government of Ethiopia is expanding the cervical screening service in different parts of the country. Health education and training on cervical cancer screening for health care provider was provided.

The findings of this study indicated that there was a significant difference in the attitude of respondents towards cervical cancer screening among different year of study level, religion, and knowledge on the benefits of screening. Year three students were less likely to have a positive attitude towards cervical cancer screening than first and second-year students. Also, year four-six students less likely to have a positive attitude towards cervical cancer screening when compared with first and second-year students. This might be due to ignorance of the senior students about cervical cancer, as they stay longer and other personal factors. Students who had good knowledge of the benefits of cervical cancer screening were less likely to have positive attitude as compared to students those who had less knowledge on the benefits of cervical cancer screening. This might also due to personal factors such as fear of the test procedures and negligence of those students who knew about cervical cancer and its screening benefits.

\section{Conclusion}

More than half of the respondents knew about risk factors and symptoms of cervical cancer and most of the students heard about cervical cancer. However, the majority of the respondents did not hear whether there are screening methods for early detection of cervical cancer. Only $21.6 \%$ of the participants knew visual inspection via acetic acid, and 51.3\% responded Pap smear. This study also showed that study participants had an unfavorable attitude towards cervical cancer screening. In general, most of the participant did not identify screening methods properly, which is an indicator of inadequate knowledge of screening methods. The study suggests that, most of them had unfavorable attitude towards screening practice. The study also revealed that field of study, year of study/ educational level were significantly associated with knowledge of the students. Knowledge on the benefit of screening, religion and year of study were significantly associated with attitude towards screening. Based on the findings of this study, more effort has to be invested to increase awareness and improve the attitude about cervical cancer screening. A further community-based study incorporating qualitative study design is required at national level to increase the representation of all females.

\section{Operational definitions}

i. Knowledgeable: Refer to those who scored mean and above the mean from the knowledge questions.

ii. Not knowledgeable: Refers to for those scored below the mean from the knowledge questions

iii. Favorable attitude: Refers to for those scored the mean and the above mean from attitude questions.

iv. Unfavorable attitude: Refers to for those scored below the mean from attitude questions.

\section{Ethical considerations}

Ethical clearance obtained from Addis Ababa University College of Health Science, school of Allied Health Science institutional review board before the starting of the fieldwork. An official letter of co-operation was written to Hawassa University, from Addis Ababa University. Hawassa University, in turn, writes an official letter of cooperation to College of Medicine and Health Sciences. Respondents informed about the objective and purpose of the study and informed consent obtained from each respondent. Moreover, all the study participants informed that they have a full right to participate or decline from participating in the study and the study participants assured for attainment of confidentiality of the information obtained from them.

\section{Funding}

Addis Ababa University as a requirement for postgraduate studies supports this research financially. The university has no role in the design of the study, collection, analysis, and interpretation of the data and in writing the manuscript.

\section{Author's contribution}

ST, DY and TG conceived the study and undertook statistical analysis. ST, DY and TG supervised the study design and statistical analysis. ST and TG contributed to the writing of the manuscript and all authors approved the submitted version of the manuscript.

\section{Acknowledgements}

The authors thank all the study participants and Addis Ababa University for financial support.

\section{Conflict of interest}

The author declares that they have no conflict of interest.

\section{References}

1. Ayinde OA, Omigbodun AO. Knowledge, attitude, and practices related to prevention of cancer of the cervix among female health workers in Ibadan. J Obstet Gynaecol. 2003;23(1):59-62.

2. Tariku R. Correlates of knowledge on cervical cancer among female students of thecollege of health science. Addis Ababa University. 2016.

3. Iliyasu Z, Abubakar IS, Aliyu MH, et al. Cervical cancer risk perception and predictors of human papillomavirus vaccine acceptance among female university students in northern Nigeria. $J$ Obstet Gynaecol. 2010;30(8):857-862. 
4. De Sanjosé S, Serrano B, Castellsagué X, et al. Human papillomavirus (HPV) and related cancers in the Global Alliance for Vaccines and Immunization (GAVI) countries. A WHO/ICO HPV Information Centre Report. Vaccine. 2012;30(Suppl 4):D1-83.

5. DeCherney A, Nathan L, Goodwin TM, et al. Current Diagnosis and Treatment: Obstetrics and Gynecology. 10th ed. McGraw-Hill Appletone and Lange; 2012.

6. Lataifeh I, Amarin Z, Khader Y. A survey of the knowledge and attitude of Jordanian obstetricians and gynecologists to cervical cancer screening. J Obstet Gynaecol. 2009;29(8):757-760.

7. Franco EL. Persistent HPV infection and cervical cancer risk: is the scientific rationale for changing the screening paradigm enough? J Natl Cancer Inst. 2010;102(19):1451-1453.

8. World Health Organization (WHO). Human Papillomavirus and Related Cancers: Summary Report Update. 2010.

9. Waktola EA, Mihret W, Bekele L. HPV and Burden of Cervical Cancer in East Africa. Gynecol Oncol. 2005;99(3Suppl 1): S201-202.

10. Gebremariam TT. Human papillomavirus-related cervical cancer and anticipated vaccination challenges in Ethiopia. Int J Health Sci (Qassim). 2016;10(1):137-143.

11. Philips Z, Avis M, Whynes DK. Knowledge of cervical cancer and screening among women in east-central England. Int J Gynecol Cancer. 2005;15(4):639-645.
12. Gakidou E, Nordhagen S, Obermeyer Z. Coverage of cervical cancer screening in 57 countries: low average levels and large inequalities. PLoS Med. 2008;5(6):e132.

13. Wu LW, Lin LP, Chen SF, et al. Knowledge and attitudes regarding cervical cancer screening among women with physical disabilities living in the community. Res Dev Disabil. 2012;33(2):376-381.

14. Jemal A, Bray F, Center MM, et al. Global cancer statistics. CA Cancer J Clin. 2011;61(2):69-90.

15. Amin MA. Knowledge, Beliefs, Attitudes, and Perceptions About Breast and Cervical Cancer and Screening Among Arabic Speaking Immigrant Women in Halifax, Nova Scotia. Cancer Nurs. 2008;39:367.

16. Olumide O, Wilcox VI, Ogunji OA. Knowledge and Attitude of Female Medical Students of Crimea State Medical University, Ukraine to Cervical Cancer and Examination. IJSS. 2014;2(3):15-24.

17. Al-Naggar RA, Low WY, Isa ZM. Knowledge and barriers towards cervical cancer screening among young women in Malaysia. Asian Pac J Cancer Prev. 2010;11(4):867-873.

18. Dhendup T, Tshering P. Cervical cancer knowledge and screening behaviors among female university graduates of the year 2012 attending thenational graduate orientation program, Bhutan. BMC Women's Health. 2014;14(1):44

19. Hoque ME. Cervical cancer awareness and preventive behavior among female university students in South Africa. Asian Pac J Cancer Prev. 2010;11(1):127-130 